\title{
Improvement Strategies Study for Outdoor Wind Environment in a University in Beijing Based on CFD Simulation
}

\author{
Xiaodan Li, ${ }^{1}$ Jing Wang $\mathbb{D}^{1}{ }^{1}$ Mahroo Eftekhari, ${ }^{2}$ Qi Qi, ${ }^{1}$ Donglin Jiang, ${ }^{1}$ Yunzi Song, \\ and Peng Tian ${ }^{1}$ \\ ${ }^{1}$ Department of Architecture, School of Mechanics and Civil Engineering, China University of Mining and Technology, \\ Beijing 100083, China \\ ${ }^{2}$ School of Architecture, Building and Civil Engineering, Loughborough University, Leicestershire LE11 3TU, UK
}

Correspondence should be addressed to Jing Wang; wjcumtb@sina.com

Received 13 May 2020; Revised 12 October 2020; Accepted 22 October 2020; Published 4 November 2020

Academic Editor: Hui Yao

Copyright (c) 2020 Xiaodan Li et al. This is an open access article distributed under the Creative Commons Attribution License, which permits unrestricted use, distribution, and reproduction in any medium, provided the original work is properly cited.

The outdoor wind environment is one of the most important factors influencing the biological environment and human comfort. The campus of China University of Mining \& Technology (Beijing) (CUMTB) is the case study for this research. PHOENICS simulation software was used to carry out a numerical simulation study of the outdoor wind environment. The pedestrian-level wind (PLW) environments for both winter and summer were investigated. Based on the numerical simulation results, the overall evaluation and subregional analysis of the campus' current outdoor wind environment were carried out. Then, according to the results and problems of wind environment assessment, improvement measures and strategies of outdoor wind environment in universities are proposed from the aspects of campus planning, single building form, and greening configuration. The main goal is to further improve the outdoor space and environment of universities in Beijing and provide general guidelines to improve the quality of the universities' wind environment effectively. The strategies can provide a reference for the same type of campus on wind environment renovation and improvement. This study can also provide data support and reference significance for outdoor thermal environment/pedestrian environment research.

\section{Introduction}

With the rapid development and continuous expansion of enrollment in universities in China, high-density university campus space has grown rapidly, and campus environmental problems have increasingly become more prominent; the overall performance of natural ventilation in the campus is poor. Pollutants and waste gas in the campus are not easy to diffuse, wind protection in winter is not good, and heat dissipation in summer is not easy. The comfort and safety of the wind environment are the important requirements of the urban environment [1]. The pedestrian-level wind (PLW) plays a key role in people's daily lives. The PLW environment affects the indoor and outdoor thermal comfort [2, 3], energy performance [4], urban ventilation [5-7], pollutant diffusion $[8,9]$, public safety $[10-12]$, and so on. The campuses are an important part of the urban system. The quality of the campuses' PLW environment affects the health, safety, study, and lives of the students, faculty, staff, and researchers. Therefore, more and more attention has been paid to the evaluation and improvement of outdoor wind environment in colleges and universities.

Campus planning, building layout, building form, and landscape setting are important factors affecting the outdoor PLW environment. Under different types of campus layout, building forms, and landscape conditions, the wind will generate a variety of airflow patterns, such as cross-ventilation, backflow, downdraft, corner wind, air stagnation zone, and eddy. Excellent airflow patterns not only ensure the comfort and safety of outdoor activities for faculty, staff, and students, but also improve air quality, enhance a natural ventilation of buildings, and reduce building energy consumption [13-15]. Unreasonable campus planning or building form may cause strong winds, downdrafts, eddies, 
etc. around the buildings, which exacerbate dust and air pollution. Unfavorable airflow patterns can even destroy buildings or structures, posing dangers to pedestrians [16]. Insufficient wind speed in dense areas can lead to air stagnation zones, which result in the accumulation of pollutants or waste gas and pose a threat to human health [17]. In summer, ambient heat is not easy to disperse in the air stagnation zone, which seriously affects human comfort. Excessive wind speeds in winter lead to increased penetration of cold air, which not only affects outdoor comfort of human body, but also increases heating load of buildings [18]. Therefore, it is of great significance to evaluate and improve the PLW environment in universities by fully considering the campus planning, building form, landscape setting, and so on.

Murakami et al. [19] conducted wind speed observations around a high-rise building for a long period of time and evaluated the wind environment at a ground level based on the opinions of the citizens of Tokyo. Sharples and Bensalem [20] conducted a wind tunnel study to investigate the airflow of the courtyard and atrium building models for nonresidential buildings within an urban setting and exposed to an urban atmospheric boundary layer. Jamieson et al. [21] studied the wind environment around six different types of buildings. Kubota et al. [17] took Japan's 22 communities as research objects to explore the quantitative relationship between residential building density and wind environment. Blocken et al. [1] used CFD simulations to analyze the PLW comfort and safety on the campus of Eindhoven University of Technology, aiming at improving the quality of the wind environment in urban areas. Ying et al. [22] used statistical analysis methods to study the effects of wind-induced airflow through the urban built layout pattern. Guo et al. [23] used the CFD simulation tool PHOENICS to evaluate and study the correlation between urban morphology and wind environment. By considering fully the wind, water, greenery, and urban form, the suggestions for urban wind environment planning were summarized. Kuo et al. [24] explored the characteristics of pedestrian-level wind environment in street canyons under different street widths, podium heights, and approaching wind directions through wind tunnel experiments.

There are few studies on the wind environment of campuses in Beijing. Beijing is one of the most densely populated cities in the world. Many university campuses are short of land, densely built, and overloaded in Beijing, which leads to environmental problems such as difficult diffusion of pollutants, wind whirlwinds in winter, and lack of ventilation and heat dissipation in summer. Therefore, it is necessary and of great practical significance to simulate and evaluate the wind environment of universities in Beijing and put forward improvement strategies. In addition, Beijing is one of the densest cities in the world, and this study will provide some reference for similar wind environment of universities in dense cities around the world.

This study focused on the campus of CUMTB and used PHOENICS CFD software to carry out the numerical simulation for the overall assessment and comprehensive analysis of the wind environment. The overall characteristics and existing problems of the wind environment were examined, and corresponding measures are proposed. Specifically, the computational geometry model of CUMTB was initially constructed. The campus was divided into five areas, A to E, to facilitate the classification discussion and detailed analysis. The turbulence model was selected, the calculation domain was delimited, the grid was divided, and the boundary conditions were set. Simulations were carried out for typical winter and summer climate. Then the overall assessment and subregional discussion of wind environment were conducted to examine and summarize the existing problems and their causes. Finally, from the aspects of campus planning, single building form, and landscape layout, the wind environment improvement strategies and specific measures to solve the problems are proposed. This study has further improved the quality of the campus environment through numerical simulation and analysis and has provided guidelines for the campus planning, renovation, and green campus construction. And it can also provide basic data support and reference significance for outdoor thermal environment and pedestrian environment research.

\section{Research Objects and Environmental and Meteorological Conditions}

2.1. Research Case Study. Beijing is the center of national higher education in China and is one of the regions with highly developed higher education buildings. Beijing has the largest number of key universities in the country. Statistics show that, by 2017, there were 92 institutions of higher education in Beijing (https://baike.baidu.com/item/\%E6\% 99\%AE\%E9\%80\%9A\%Е9\%AB\%98\%E7\%AD\%89\%E9\%99\% A2\%E6\%A0\%A1). Among them, there are about 26 colleges and universities in the Haidian district of Beijing, which is highly representative of the university-gathering area [25]. Therefore, as a campus in the Haidian district, the CUMTB campus was selected as this research case study.

CUMTB is close to Tsinghua East Road on the north side and Xueyuan Road to the west side. The campus contains variety of complex spaces such as teaching and office areas, accommodations and living areas, and family communities. The teaching and office areas are clustered in the eastern part of the campus. Accommodation and living areas are mostly located in the middle of the campus. The family community is mainly located on the west side of the campus. In order to facilitate clear expression and detailed analysis, the entire campus was roughly divided into five areas and numbered by $\mathrm{A} \sim \mathrm{E}$. The dotted area is the scope of the campus (Figure 1).

2.2. Environmental Meteorology. The GB 50176-2016 "Code for Thermal Design of Civil Buildings" divides China into five districts. Beijing belongs to the cold region of China. Campus planning or single building design in the cold region of China should mainly consider avoiding cold wind in winter and promoting ventilation and heat dissipation in summer [26]. Beijing is in the eastern part 


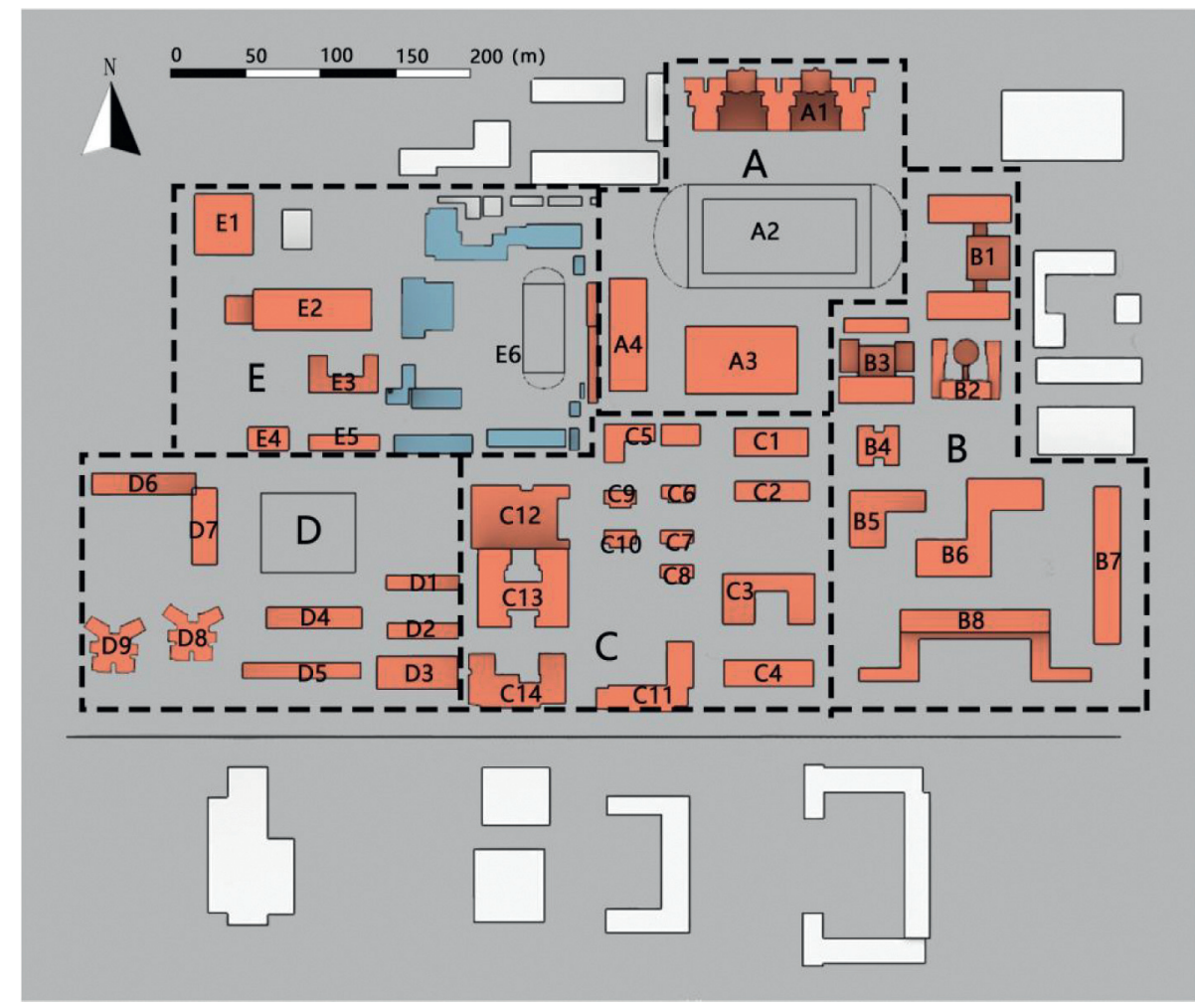

FIgURE 1: The subregion description of CUMTB campus.

of North China. Beijing's climate belongs to the typical temperate continental monsoon climate, hot and rainy in the summer, cold and dry in the winter, and mild in spring and autumn. Therefore, in this study, winter and summer were selected for simulation due to wide range of climate. The conditions of various parameters of the seasonal wind direction were set up according to data from the China Meteorological Information Center [27]. As shown in Figure 2 and Table 1, Northerly wind prevails in winter, and southerly wind prevails during summer in Beijing. The frequency of maximum wind direction is $12 \%$ in summer and $14 \%$ in winter.

\section{Overview of Research Methods and Processes}

At present, the research methods of the urban and building wind environment mainly include three methods: field measurement study, wind tunnel tests, and Computational Fluid Dynamics (CFD) numerical simulation. The field measurement study is time-consuming and labour-intensive, and the scale of the research area is limited. Wind tunnel tests require costly and specialized equipment. CFD numerical simulation has become the main research method by virtue of its fast calculation speed and high efficiency $[1,14,22,28,29]$.

There are a lot of CFD simulation software, each with its scope and characteristics, such as PHOENICS, ANSYS FLUENT, AIRPAK, and ENVI-MET. PHOENICS was selected for this research since it is easy to operate, efficient in simulation prediction, and fast in calculation speed, and parameter setting can be set directly. The
FLAIR module for building and regional wind environment simulation in PHOENICS software was selected for this study [30]. Figure 3 is technology roadmap of this research.

\subsection{Establishment of the Campus Computational Geometry} Model. tInitially, AutoCAD construction drawings of the campus were verified and updated by field survey and mapping. Then, Rhino was used for modeling and colour identification. The approximate size of the entire campus is $722 \mathrm{~m} \times 606 \mathrm{~m} \times 60 \mathrm{~m}$. In order to reduce the computational load of the computer and to speed up the calculation, the small slope of the campus ground and the small concave and convex changes of the buildings were ignored, and the buildings were processed into regular geometric forms; that is, the campus model was simplified appropriately. During modeling, no loopholes, gaps, and broken lines were followed to ensure the integrity and accuracy of the model. Large-scale buildings around the campus were also included in the model since they are important factors affecting the wind environment of the campus. The geometric model includes the CUMTB campus, which was marked in brown-red; E6 is the affiliated middle school of CUMTB and its family buildings, which was marked in blue-gray; main massive buildings around the campus were shown in gray-white (Figure 4). The model files with extensions of. stl and .3ds were exported and imported into PHOENICS for numerical simulation of the wind environment of the CUMTB campus. 


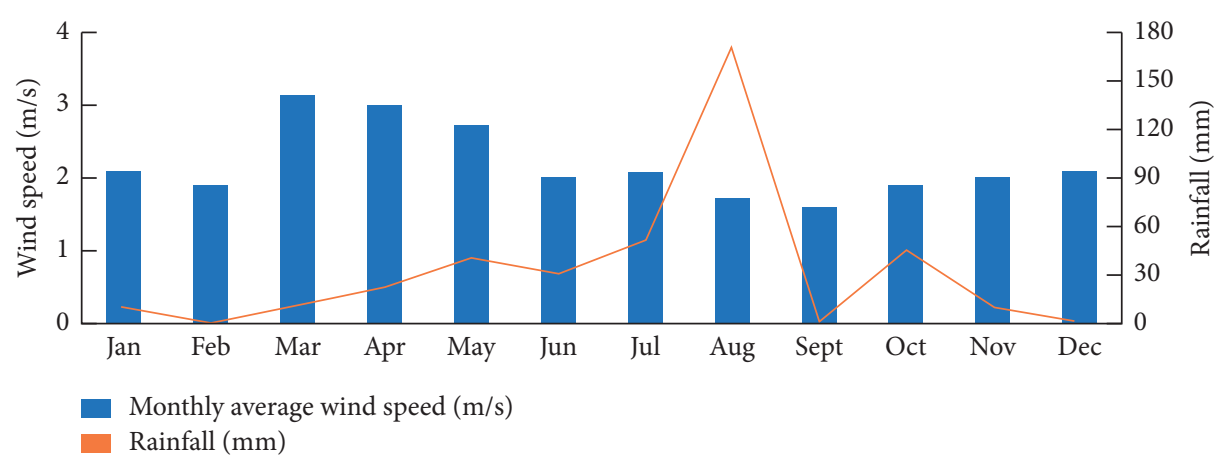

FIGURE 2: Monthly changes of average wind speed and rainfall capacity in the observatory.

TABLE 1: The setting of simulation parameters in winter and summer.

\begin{tabular}{lcccc}
\hline $\begin{array}{l}\text { The parameter } \\
\text { types }\end{array}$ & $\begin{array}{c}\text { Seasonal outdoor average } \\
\text { wind speed }(\mathrm{m} / \mathrm{s})\end{array}$ & $\begin{array}{c}\text { The maximum wind } \\
\text { direction in a season }\end{array}$ & $\begin{array}{c}\text { Average wind speed in maximum } \\
\text { outdoor directions }(\mathrm{m} / \mathrm{s})\end{array}$ & $\begin{array}{c}\text { Frequency of maximum } \\
\text { wind direction }(\%)\end{array}$ \\
\hline Summer & 2.2 & SE & 3.0 & 12 \\
Winter & 2.7 & NNW & 4.7 & 14 \\
\hline
\end{tabular}

Note. SE: southeast; NNW: north-northwest, according to the definition of wind direction, the wind direction of the wind blowing from the azimuth angle in the range of $337.5^{\circ} \pm 11.25^{\circ}$ is recorded as NNW.

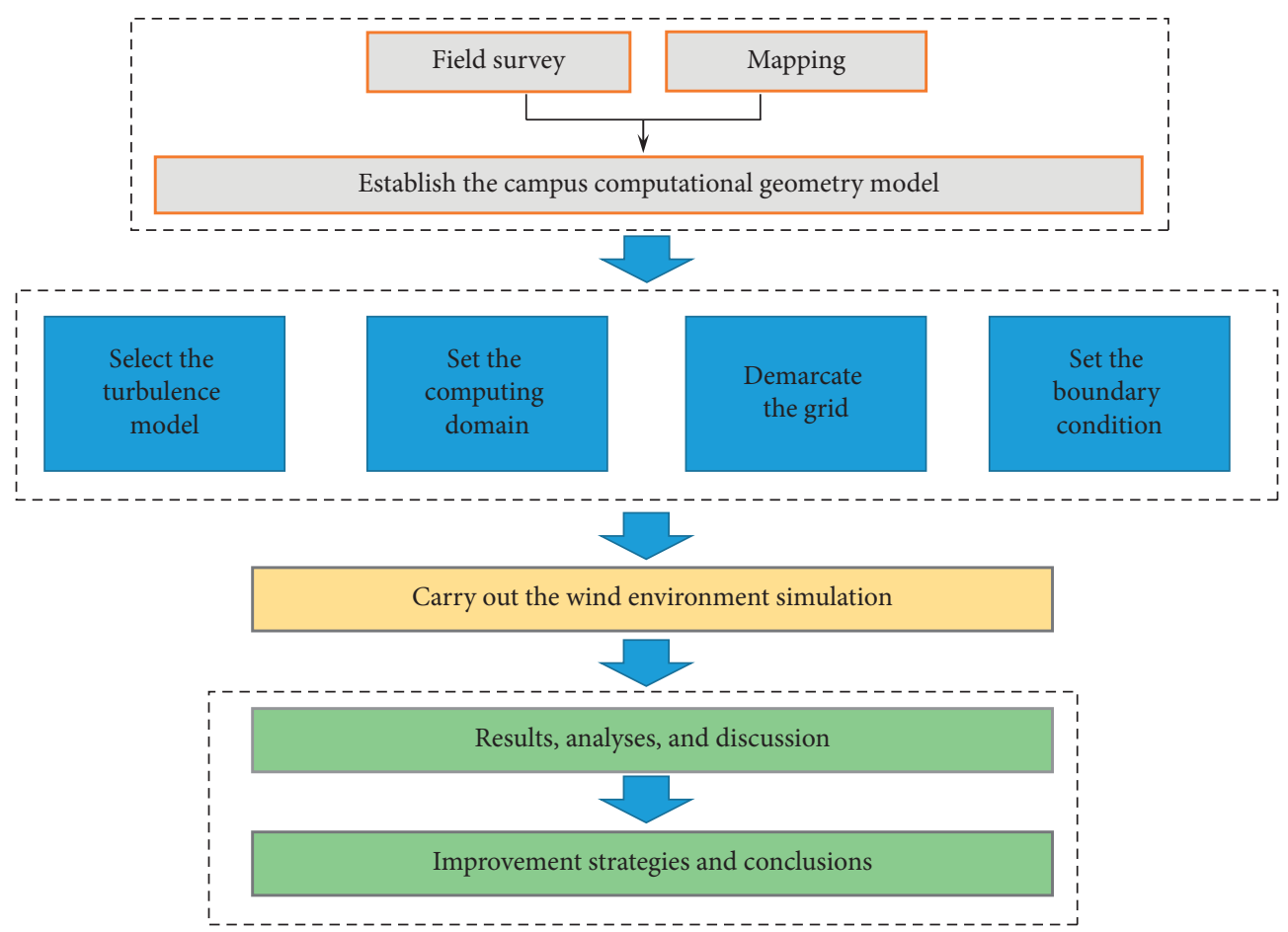

FIGURE 3: Technology roadmap of the research.

3.2. Selection of the Turbulence Model. PHOENICS software contains a variety of turbulence models, including DNS, Large Eddy Simulation (LES), and Reynolds Average Navier-Stokes (RANS). Because the accuracy and calculation amount of these models are different, they are suitable for application in different fields. RANS include the Spalart-Allmaras model, the standard $K-\varepsilon$ model, the RNG $k-\varepsilon$ model, the realizable $K-\varepsilon$ model, and the Reynolds stress model (RSM).
Among the RANS models, the standard $K-\varepsilon$ model is the most commonly used turbulence model in engineering, with a moderate amount of computation, less computation time, lower cost, small fluctuation, and high accuracy in numerical computation. In general, the airflow around the building belongs to incompressible low-speed turbulence, which conforms to the Boussinesq hypothesis. The contact of the airflow with the buildings forms a restricted flow. The standard $K-\varepsilon$ model models restricted flow (with wall 


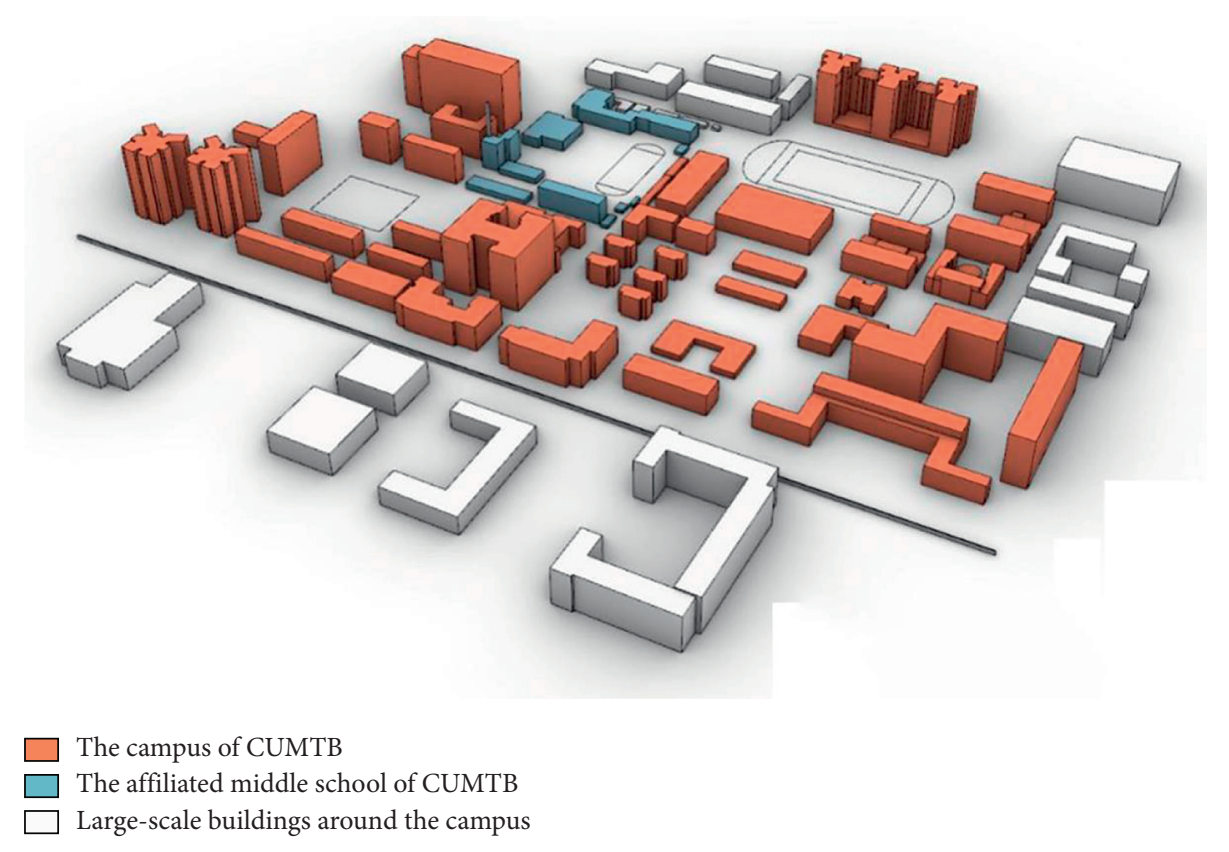

FIgURE 4: Computational geometry model of the CUMTB campus.

constraints) well and therefore is widely used in low-speed turbulence numerical simulation. In this study, the standard $K-\varepsilon$ turbulence model was used. In the modeling process, when the energy equation is closed, the effect of temperature is not considered, and the user-defined source term is not considered, the following equations can be obtained [31-33].

Continuity equation:

$$
\frac{\partial u_{i}}{\partial x_{i}}=0
$$

Turbulence kinetic energy $k$ :

$$
\frac{\partial(\rho k)}{\partial t}+\frac{\partial\left(\rho k u_{i}\right)}{\partial x_{i}}=\frac{\partial}{\partial x_{j}}\left[\left(\mu+\frac{\mu_{t}}{\sigma_{k}}\right) \frac{\partial k}{\partial x_{j}}\right]+G_{k}-\rho \varepsilon .
$$

Dissipation rate $\varepsilon$ :

$$
\frac{\partial(\rho \varepsilon)}{\partial t}+\frac{\partial\left(\rho \varepsilon u_{i}\right)}{\partial x_{i}}=\frac{\partial}{\partial x_{j}}\left[\left(\mu+\frac{\mu_{t}}{\sigma_{\varepsilon}}\right) \frac{\partial \varepsilon}{\partial x_{j}}\right]+\frac{C_{1 \varepsilon} \varepsilon}{k} G_{k}-C_{2 \varepsilon} \rho \frac{\varepsilon^{2}}{k}
$$

Turbulent viscosity $\mu_{t}$ :

$$
\begin{aligned}
\mu_{t} & =\rho C_{\mu} \frac{k^{2}}{\varepsilon}, \\
C_{1 \varepsilon} & =1.44, \\
C_{2 \varepsilon} & =1.92, \\
\sigma_{k} & =1.0, \\
\sigma_{\varepsilon} & =1.3,
\end{aligned}
$$

where $\mu_{t}$ is turbulent viscosity or eddy viscosity; $u$ is an instantaneous velocity; $x$ is a distance; $\rho$ is density in $\mathrm{kg} / \mathrm{m}^{3} ; t$ is the time; $k$ is the turbulence kinetic energy; $\varepsilon$ is the turbulent dissipation rate; $\sigma_{k}$ is the Prandtl number corresponding to $k ; \sigma_{\varepsilon}$ is the Prandtl number corresponding to $\varepsilon ; C_{1 \varepsilon}$ and $C_{2 \varepsilon}$ are empirical constants.

3.3. Computational Domain of Models. The calculation domain is determined according to the size of the actual geometric model. The domain setting affects simulation accuracy, calculation time, and efficiency. Excessive calculation domain leads to increased calculation volume and longer calculation time. If it is too small, the flow field will develop insufficiently and the simulation accuracy of results is greatly reduced.

Concerning computational domain of models, various guidelines have been proposed. Tominaga et al. and Mochida et al. suggested that the boundaries should be set $5 \mathrm{H}$ or more away from the building to ensure the full development of wind fields, where $H$ is the height of the target building [34-36]. China's standard JGJ/T 449-2018 [37] recommended that the distance from the inflow and outlet boundary to the building edge should be greater than $5 \mathrm{H}$ and $10 H$, respectively.

Based on these suggestions, the dimensions of the computational domain were set as $1983 \mathrm{~m} \times 1327 \mathrm{~m} \times 660 \mathrm{~m}$. The inflow and lateral boundary were set as $6 \mathrm{H}$ away from the buildings. The length from the outlet boundary to the buildings' edge is $11 \mathrm{H}$; detailed settings are shown as in Figure 5 .

According to the scale of the geometry and calculation domain of the campus, the number of iteration steps was set to 5000, which was to control the calculation time to improve the accuracy of the simulation results, as presented in Figure 6 (see Figures 7-10).

3.4. Computational Grid of Models. Drawing reasonable grid density and numbers significantly improves the calculation 


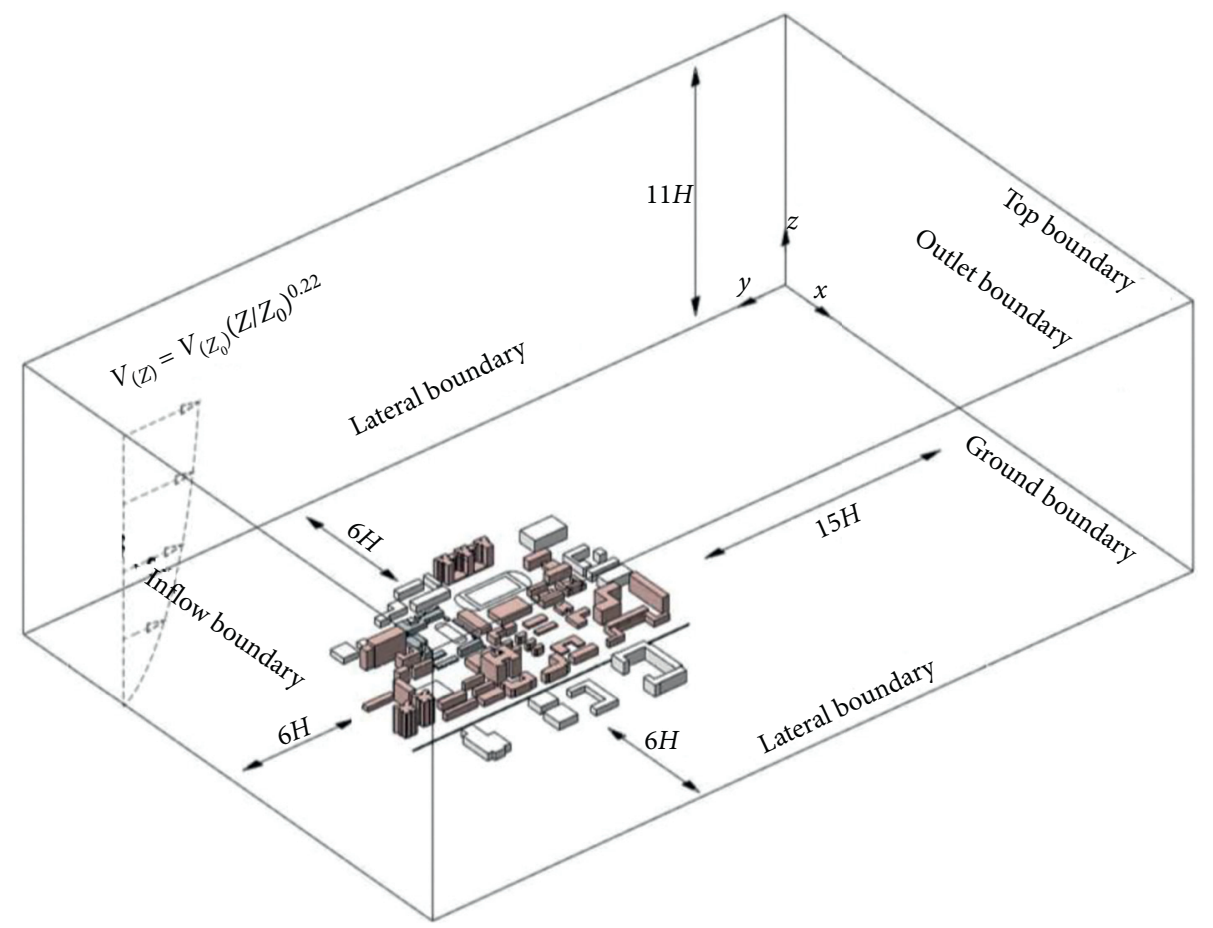

Figure 5: The computational domain.

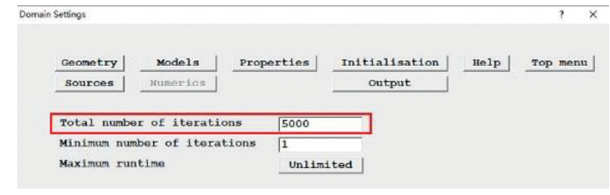

Figure 6: The simulation interations.

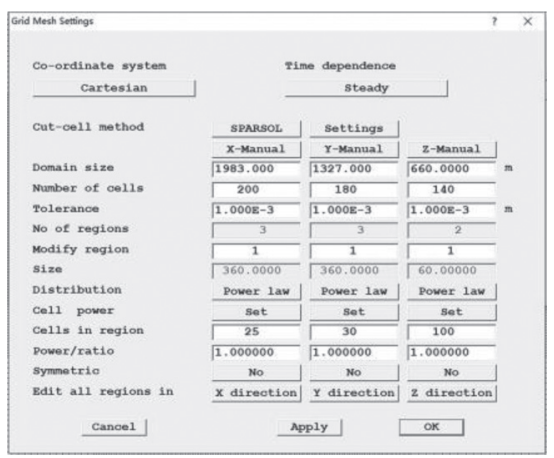

Figure 7: The grid setting of $X, Y$, and $Z$ axis of the CUMTB campus.

accuracy and efficiency. In this study, the grid division adopted two forms of coexistence modes: the uniform grid and the uneven grid. Dense grids were used in the campus buildings area, while the outer area of the buildings area was arranged with sparse grids, forming a dense internal and sparse external grid structure. Based on the size of the computational domain, the final grids of computational domain for this simulation were divided into about 5040000 .
3.5. Boundary Conditions. Setting reasonable boundary conditions is also a critical step to ensure accurate simulation results. The lower atmospheric layer belongs to incompressible fluids. Velocity-inlet boundary is applicable to the incompressible fluids. Therefore, type of inlet was velocityinlet during numerical simulation in this study, as presented in Figure 5. Due to the friction on the Earth surface, the outdoor wind speed above the ground increases with height, forming gradient wind. So, we adopted power law wind profile to fit the actual atmospheric boundary layer, namely,

$$
\frac{v_{(z)}}{v_{\left(z_{0}\right)}}=\left(\frac{z}{z_{0}}\right)^{\alpha},
$$

where $v_{(z)}$ is the wind velocity at the height of $z$; $v_{z(0)}$ refers to the wind velocity at the height of $z_{0} ; z_{0}=10 \mathrm{~m} ; \alpha$ is ground roughness index; $\alpha$ is 0.22 according to China's standard JGJ/T 449-2018 [37] in this study. The wind profile is presented in Figure 5.

As for the exit boundary conditions, to ensure the fluids fully developed, the boundary conditions were set as the free exit boundary. Other plane and building exterior surface adopted wall boundary condition.

\section{Results and Analyses}

The PLW environment is an important factor affecting human comfort and safety. Human comfort assessment and many related standards are mostly defined based on the pedestrian height. Thus, the horizontal section of the pedestrian height $Z=1.5 \mathrm{~m}$ on the campus was selected for simulation. According to relevant standards and human comfort research results, $5.0 \mathrm{~m} / \mathrm{s}$ is the upper limit of wind 


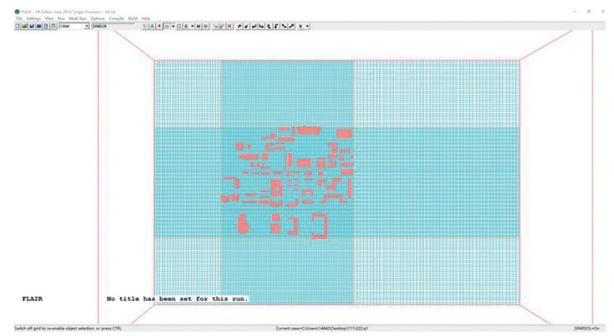

FIgURE 8: The grid of $X Y$ plane of the CUMTB campus.

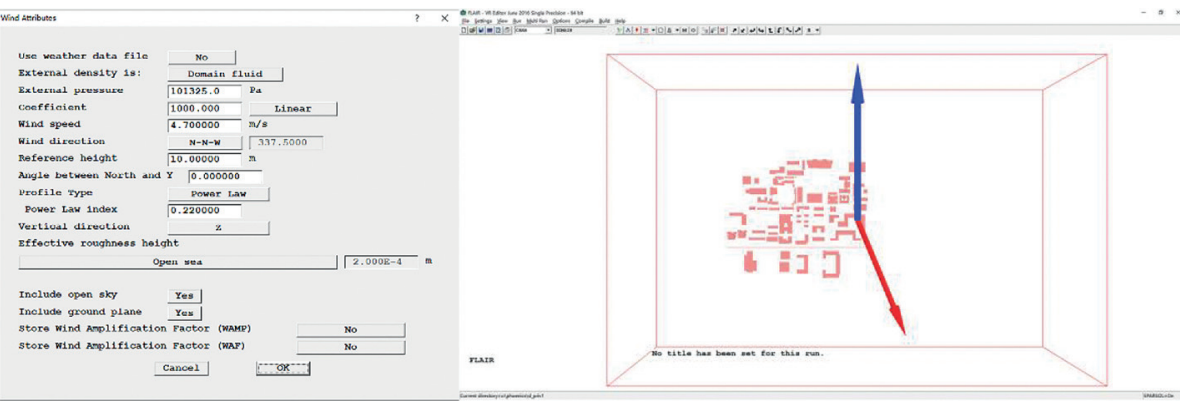

FIGURE 9: Wind attributes in winter.

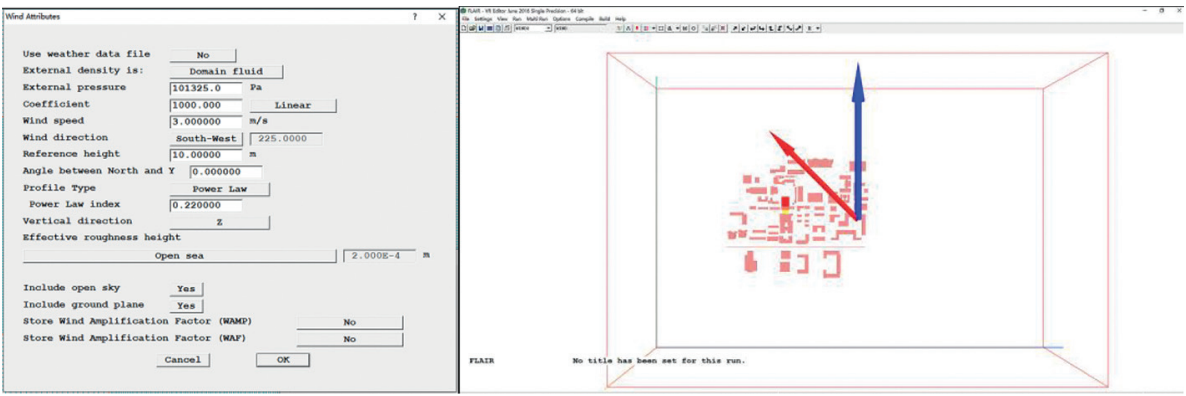

Figure 10: Wind attributes in summer.

speed for human comfort [20]. For most activities, wind speeds greater than $5.0 \mathrm{~m} / \mathrm{s}$ are considered uncomfortable [17]. In addition, research on environmental hygiene shows that a wind speed lower than $0.4 \mathrm{~m} / \mathrm{s}$ is not conducive on the discharge of pollutants in the air. If the outdoor wind speed reaches $7.5 \mathrm{~m} / \mathrm{s}$, pedestrians feel the force of the wind. When the wind speed is greater than $10.0 \mathrm{~m} / \mathrm{s}$, pedestrians experience difficulty moving around [14, 38-41]. The impact of wind on the human body is shown in Table 2 . The wind speed in Table 2 is normally referred to as the speed of wind at $10 \mathrm{~m}$ above an open terrain, and the wind speed at the pedestrian level is roughly $70 \%$ of the tabulated values [13].

4.1. Wind Conditions in Winter. The prevailing wind direction in winter is the north-northwest wind (NNW). According to the wind velocity vector map and wind velocity contour map at $Z=1.5 \mathrm{~m}$ in winter (Figures 11 and 12 ), the wind speed in the entire campus was between $0.00 \mathrm{~m} / \mathrm{s}$ and $6.00 \mathrm{~m} / \mathrm{s}$. The wind speed in a small part of the area exceeded $4.80 \mathrm{~m} / \mathrm{s}$, and in most areas, the speed was below $4.80 \mathrm{~m} / \mathrm{s}$. Area $\mathrm{C}$ displays a poor wind environment. About 35\% of Area $\mathrm{C}$ had extremely low wind speed or no wind. Therefore, the air was trapped, which affects the air quality in Area C. High wind speeds and wind vortices were concentrated at the corners of the windward side of peripheral buildings in the northwest and northeast of the campus and on the campus's narrow roads north-south and east-west. High-speed wind vortices hinder outdoor activities of pedestrians and even pose a threat to their safety.

4.1.1. Area $A$. The wind speed in the overall area was about $3.75 \mathrm{~m} / \mathrm{s}$. The wind speed was relatively good, and the wind environment was relatively comfortable. There were strong high-speed winds at the northeast corner and the narrow walkway on the west side of A1. These wind speeds were up to about $6.00 \mathrm{~m} / \mathrm{s}$, mainly because high-speed winds were easy to appear at the corners of the windward side of buildings in winter and exacerbated by the wind-inducing effect of long and narrow roads.

4.1.2. Area $B$. The wind speed in the whole area was relatively stable, about $1.50 \mathrm{~m} / \mathrm{s}-4.50 \mathrm{~m} / \mathrm{s}$, and the overall wind environment was relatively comfortable. At the secondary entrance of the campus (the north area of B6 and B7), the 
TABLE 2: Types of wind and effects of wind on people.

\begin{tabular}{lccc}
\hline $\begin{array}{l}\text { Beaufort } \\
\text { no. }\end{array}$ & Description & $\begin{array}{c}\text { Wind speed } \\
(\mathrm{m} / \mathrm{s})\end{array}$ \\
\hline 2 & Light breeze & $1.6-3.3$ & Effect \\
3 & Gentle breeze & $3.4-5.4$ & $\begin{array}{c}\text { Wind felt on face } \\
4\end{array}$ \\
5 & Moderate breeze & $5.5-7.9$ & $\begin{array}{c}\text { Hair disturbed; clothing flaps; newspaper } \\
\text { challenging to read } \\
\text { Raises dust and loose paper; } \\
\text { hair disarranged }\end{array}$ \\
6 & Fresh breeze & $8.0-10.7$ & $\begin{array}{c}\text { Wind force felt by body; possible stumbling when } \\
\text { entering a windy zone }\end{array}$ \\
7 & Strong breeze & $10.8-13.8$ & $\begin{array}{c}\text { Umbrellas used with difficulty; hair blown straight; difficult in } \\
\text { walking steadily; wind noise on ears unpleasant } \\
\text { Inconvenience felt when walking }\end{array}$ \\
9 & Near gale & $13.9-17.1$ & $\begin{array}{c}\text { Generally impedes progress; great difficulty } \\
\text { with a balance in gusts } \\
\text { People blown over }\end{array}$ \\
\hline
\end{tabular}

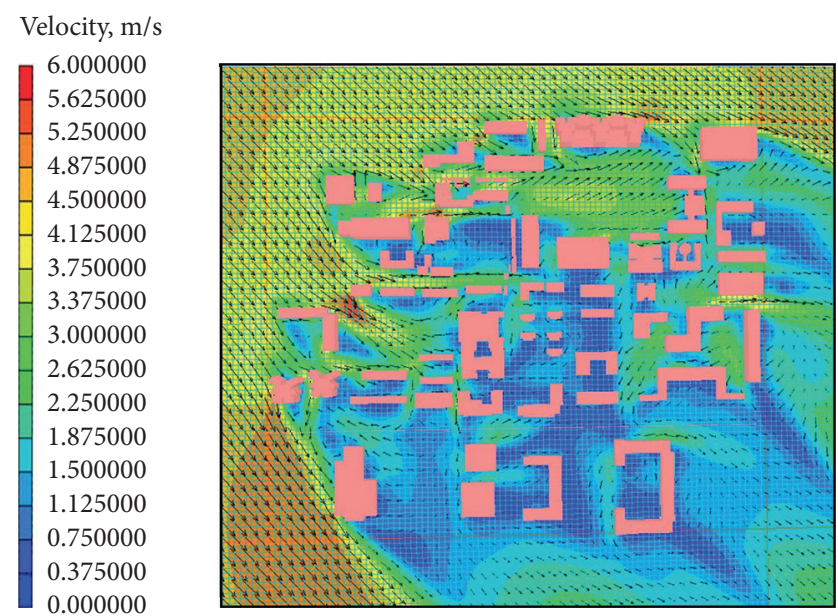

FIgURE 11: The wind velocity vector illustration at $Z=1.5 \mathrm{~m}$ in winter.
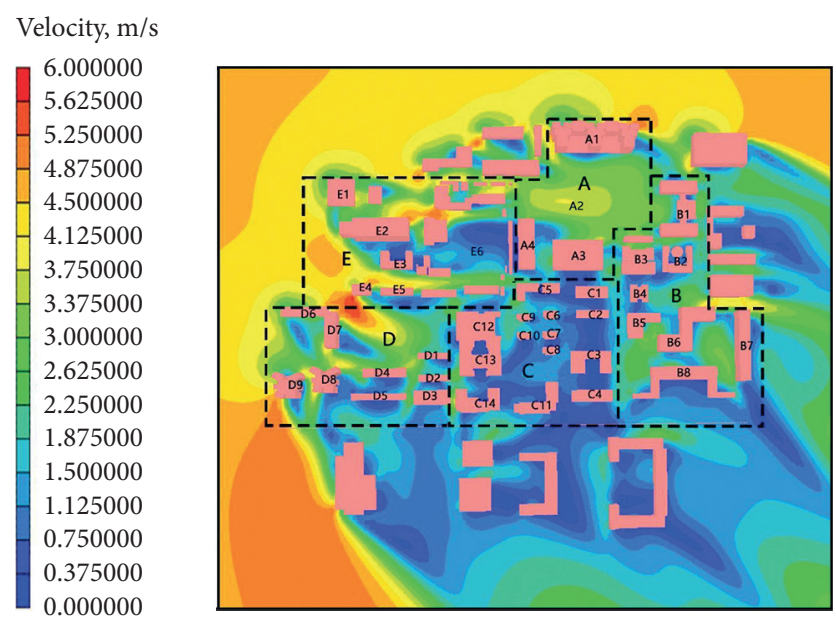

Figure 12: The wind velocity contour map at $Z=1.5 \mathrm{~m}$ in winter.

wind speed at the corner of the windward side was increased sharply due to the narrow channel effect and fewer sheltered buildings in the west. There was strong downwind along the north facades of the buildings B6 and B7. The airflow in this area was relatively turbulent and the maximum wind speed was close to $5.00 \mathrm{~m} / \mathrm{s}$. In winter, pedestrian activities and human comfort are affected here. Due to the mutual influence between $\mathrm{B} 2$ and $\mathrm{B} 3$ and their closeness, there was a small area of low-speed wind area at their southward leeward side where the wind speed dropped to $0.375 \mathrm{~m} / \mathrm{s}$ or below. In addition, the wind speed in some areas on the south side of B8 was low. Although it was good for thermal insulation in winter, too low wind speed seriously affects air quality.

4.1.3. Area $C$. This area mainly includes dormitories and dining halls. The row layout of multiple dormitory buildings has a blocking effect on the dominant wind, resulting in a large area of low-speed wind area, with the wind speed dropping to $0.375 \mathrm{~m} / \mathrm{s}$ or even lower in some areas, especially in the C1-C4 area and the northwest of C11. Although the low wind speed effectively reduces heat loss in winter, a large area of low wind speed leads to the accumulation of air pollutants.

4.1.4. Area $D$. This area is mainly used for residential buildings. Most places had comfortable wind speeds, ranging from $1.125 \mathrm{~m} / \mathrm{s}$ to $3.75 \mathrm{~m} / \mathrm{s}$; however, a large area of wind vortices occurred at the northeast corner of D6 and D7, and a small range of strong high-speed winds also appeared at the building corners of D4, D8, and D9. Therefore, when planning or renovating, attention should be paid to the optimization of the building corners to avoid the strong high-speed winds and wind vortices.

4.1.5. Area E. This area is mainly the teaching area and experimental area. It also includes the affiliated middle school of CUMTB. The wind speed of the overall area was relatively comfortable; however, wind vortices appeared at the northeast corner of E2 and at the corners of the windward side of the buildings in E6. These vortex areas were less comfortable and prone to safety issues.

4.2. Wind Conditions in Summer. The dominant wind in summer is the southeast wind (SE). From the wind velocity vector diagram and wind velocity contour map of the 
simulation results at $Z=1.5 \mathrm{~m}$, the overall wind speed on the campus was within $4.80 \mathrm{~m} / \mathrm{s}$, which does not exceed the upper limit of human comfort wind speed, $5.00 \mathrm{~m} / \mathrm{s}$ (Figures 13 and 14). There were almost no high-speed wind zones. In densely populated areas and around large-scale buildings, due to their greater resistance to wind, areas A to $\mathrm{D}$ of the campus all had large areas of wind shadow areas, and the wind speed dropped to $0.375 \mathrm{~m} / \mathrm{s}$ or even lower, affecting the air circulation seriously.

4.2.1. Area A. North of A2, there was not much shelter from buildings, and the wind speed was mostly in the range of $1.125 \mathrm{~m} / \mathrm{s}$ to $3.75 \mathrm{~m} / \mathrm{s}$. The overall wind environment was relatively comfortable, which was suitable for teachers and students to perform outdoor sports in summer; however, due to the blocking of large-scale buildings such as B1, B2, B3, A3, and A4, a large area of wind shadow appeared in the south of Area A which is the lee side of $\mathrm{A} 3$, and the ventilation effect was relatively weak.

4.2.2. Area $B$. The closeness of $\mathrm{B} 2$ and $\mathrm{B} 3$, the large volume of B6 in the south, and the surrounding off-campus buildings blocked the wind create a very large wind shadow area in the entire cluster area of $\mathrm{B} 1 \sim \mathrm{B} 6$, with most wind speeds below $0.75 \mathrm{~m} / \mathrm{s}$ and even $0.00 \mathrm{~m} / \mathrm{s}$. This is extremely detrimental to the heat dissipation and air circulation of various classrooms, offices, laboratories, etc. in Area B in summer. Pedestrians feel air stagnation, which significantly affects human wind comfort and thermal comfort. The wind speed in areas B7 B8 was more comfortable than elsewhere in Area B, mostly between $1.125 \mathrm{~m} / \mathrm{s}$ and $3.75 \mathrm{~m} / \mathrm{s}$.

4.2.3. Area $C$. Most wind speeds in Area $C$ were in the range of $1.125 \mathrm{~m} / \mathrm{s} \sim 3.375 \mathrm{~m} / \mathrm{s}$, and the wind environment was relatively comfortable. There were some wind shadow areas in the $\mathrm{C} 1 \sim \mathrm{C} 3$ and $\mathrm{C} 5 \sim \mathrm{C} 6$ areas due to the blocking effect of multiple dormitory buildings on the dominant wind. The wind speed dropped below $0.75 \mathrm{~m} / \mathrm{s}$, and the ventilation was not ideal.

4.2.4. Area D. The wind speeds in most places of Area D were from $0.75 \mathrm{~m} / \mathrm{s}$ to $3.375 \mathrm{~m} / \mathrm{s}$, and the wind environment was comfortable; however, on the north of D4, there were some wind shadow areas, and the wind speed dropped below $0.75 \mathrm{~m} / \mathrm{s}$, which produces a sweltering feeling and stagnation in the summer and is not conducive to the ventilation of the building space.

4.2.5. Area E. Many wind shadows appear in E6 in Area E, which may be due to its compact layout. Its layout can be opened in the windward direction in summer to introduce wind. There were also some shadow areas near E1 and E2. The wind speed in other areas was relatively stable, ranging from $0.75 \mathrm{~m} / \mathrm{s}$ to $3.375 \mathrm{~m} / \mathrm{s}$, which was more comfortable.

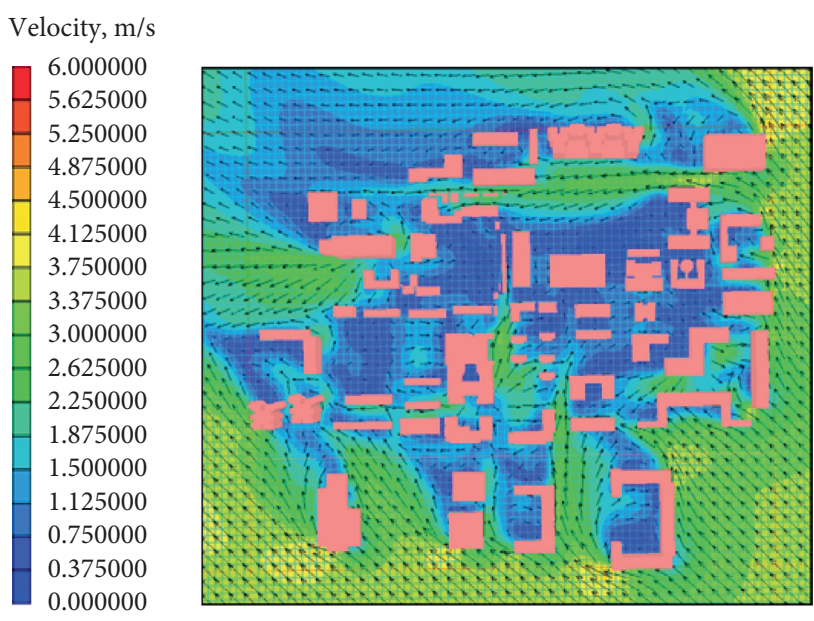

FIgURE 13: The wind velocity vector illustration at $Z=1.5 \mathrm{~m}$ in summer.

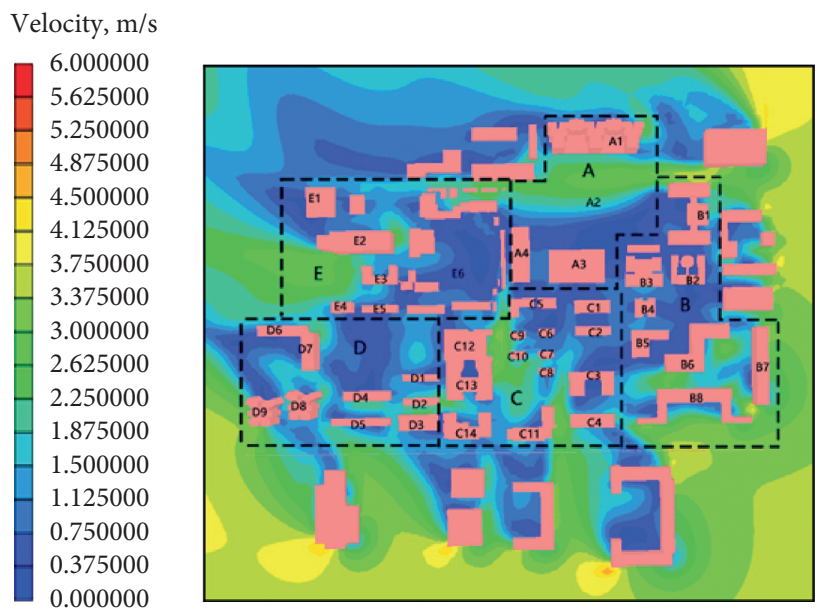

Figure 14: The wind velocity contour map at $Z=1.5 \mathrm{~m}$ in summer.

\section{Improvement Strategies}

There are many factors affecting the distribution of the flow field inside and around the campus, such as climatic conditions, terrain conditions, campus planning, road layout, building location, building mass and form, and building orientation. Other factors include natural wind characteristics, underlying surfaces, human activities, and greening. Therefore, in the planning, design, and reconstruction of the campus, various factors should be comprehensively considered.

Based on numerical simulation results, following the principles of wind prevention in winter and ventilation consideration in summer, improvement measures were explored to improve the comfort of the campus wind environment during the winter and summer. The improvement strategies were carried out for the overall planning of the campus, single building form, building wind and shadow area optimization, and greening configuration to reduce the formation of unfavorable wind environments and to create a campus with a comfortable wind environment [42]. 
5.1. Improvement Strategies of the Overall Campus Planning. Throughout the city, each university campus is an independent individual building, with its interface and interior space. For the campus, the opening of the windward interface for the building complexes is the primary factor in improving the wind environment.

According to the results (Figures 11 and 12), many highspeed wind vortices appeared on the windward interface of districts such as A1, E2, E4, D6, and D7 in the winter. In the winter, the principle of wind protection should be followed, so the openings of the windward interface should be strictly controlled and appropriately reduced to avoid the cold wind from penetrating. The three districts, A, D, and E, are located in the peripheral interface area where the wind prevails. The notches of the peripheral building interface in these three areas should be far away from the prevailing wind direction in the winter, and L-shaped and U-shaped building form with a strong enclosure should be selected to resist excessive cold wind penetration in winter. In the summer, the natural ventilation of the entire campus should be continuously promoted. The number and size of the openings to the windward interface in the southeast of the campus can be increased. The campus should adopt a pattern of high in the northeast and low in the southeast, or a combination of high front and low back in regard to the control of the height of a group of buildings. There are no contradictions in achieving the winter wind protection and summer ventilation of the campus because the wind direction in the winter and summer seasons in Beijing is roughly opposite.

\subsection{Improvement Strategies of a Single Building}

5.2.1. The Improvement Strategies for Building Corner Wind. During the winter, wind vortices appeared at the northeast corner of A1 (Figures 11 and 12). The area on the north side of A1 was very cold and windy, which dramatically affects passing pedestrians. Meanwhile, there were also high-speed wind vortices around D6, D7, E4, and the northeast corner of E2. The boundaries of many individual buildings were right-angled or acute-angled due to the requirements and purpose of building structure and aesthetics. The airflow was diverted at the corners of the windward side of these buildings, making it easy to form strong high-speed winds and wind vortices. The fundamental solution to reduce this phenomenon is to optimize the shape of the building boundary. If the boundary of the building is smoother and flatter, the change in the pressure difference between the windward and leeward sides is smaller, which significantly weakens the strong wind current.

The shape of buildings such as A1 and E2 was optimized: the right angle of the building was passivated and the wall damping was increased. After the implementation of optimization measures, it can be observed that the highspeed wind vortices at the northeast corner of A1 and E2 can be greatly alleviated, as presented in Figure 15. Therefore, when designing and renovating the campus, the boundary shapes of the buildings should be rounded and smooth, especially the corners of the windward side. For example, the sharp turning parts of the building can be curved, or the damping at the corners of the building can be increased to reduce the air shunt intensity. Further construction details, such as increasing the unevenness of the wall moldings, may also be conducted. Moreover, implementing structures and plants and increasing the unevenness of the wall moldings can be used to reduce the undesirable wind effects.

5.2.2. The Improvement Strategies for Downdraft Wind of Buildings. The airflow at the secondary entrance on the east side of the campus (the north area of B6 and B7) was relatively disordered (Figures 11 and 12). In winter, the airflow forms a downdraft along the north facade of the buildings B6 and B7, and a mixture of return air and incoming air, as well as air from other directions, formed a vortex area near the ground. This is due to the building's blocking effect on the wind. The speed of downdraft was generally faster, which has a severe impact on PLW environment. The fundamental solution to resolve the downdraft area is to increase the surface roughness of the building facade and increase the building's obstruction to the airflow, which buffers and weakens the downwind. For example, engineer or architect can increase the roughness of the building facade by setting reasonable balconies, terraces, and vertical greening; when renovating and designing, it is also possible to build retreat and changes in the unevenness of the building facades and set up podiums and plant trees, to relieve the downdraft speed and energy.

5.3. Improvement Strategies for the Wind Shadow Area of the Building. The size of the wind shadow area of the building is related to the layout of the building group, the building form and size, and the prevailing wind direction of the building. These factors interact and affect the overall campus wind environment. Researchers have verified that adjusting the overall layout of the building group, the building orientation (that is, the angle between the main body and prevailing wind direction of the building), and the shape of the building can change the size of the wind shadow area. For example, adjusting the building orientation of the determinant building group can adjust the area of the wind shadow effectively; the rectangular plane can be bent by a specific arc to reduce the wind shadow; the square building plane can be rotated by a certain angle to reduce the wind shadow.

In winter, the wind shadow area in Area $C$ was large, the overall wind speed was low, and the air was trapped (Figures 11 and 12). The interior buildings in Area $C$ were mostly in a row layout, so the angle between some buildings and the prevailing wind direction in winter can be adjusted to guide the airflow into the building group. Arc transformation on the building planes, such as C1, C2, C4, and C5, could also be conducted. These measures can reduce the area of the wind shadow in winter and promote the ventilation in summer.

In summer, the wind shadow areas in areas A, B, D, and E were relatively large, and the air stayed hot, which significantly affected the wind comfort of the human body (Figures 13 and 14). When the height or horizontal dimension of the building is 

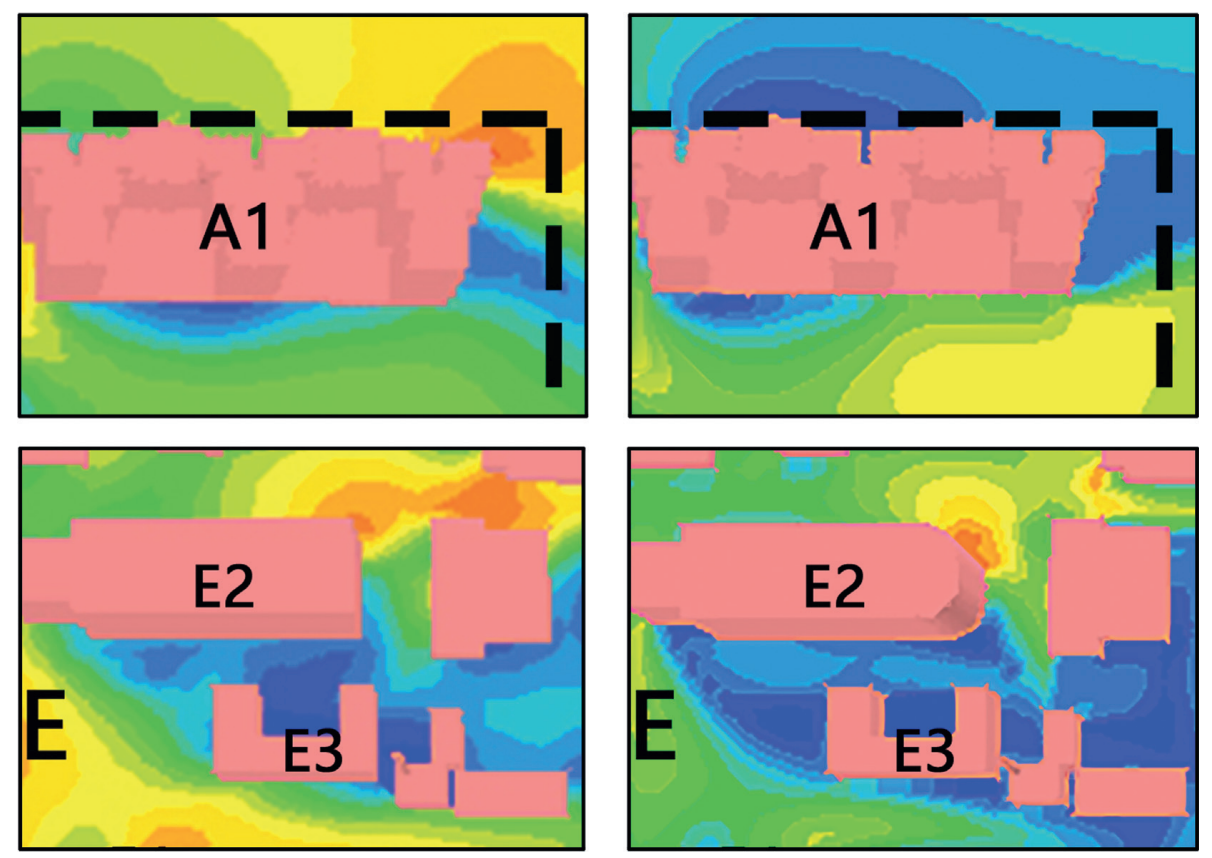

FIGURE 15: The comparison diagram before and after implementation of optimization.

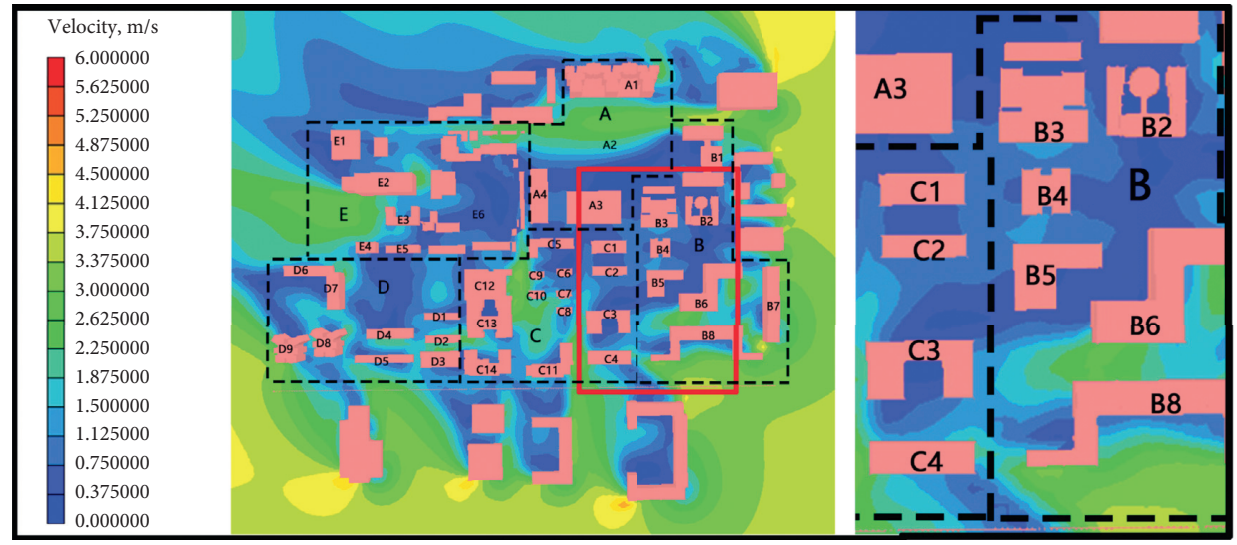

(a)

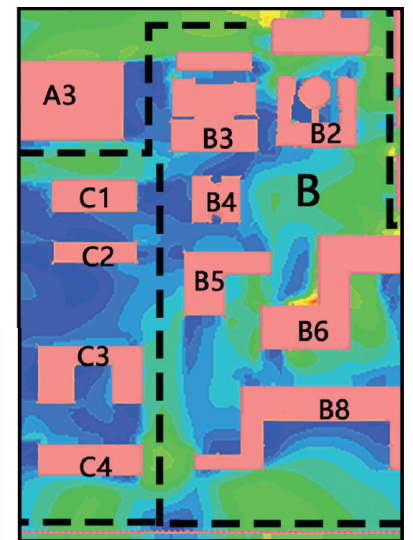

(b)

FIgURE 16: The comparison picture before and after implementation of optimization. (a) The original; (b) the optimized.

large, the reduction of the wind shadow area by changing the plan of the building is limited. The length of B6 was longer, and the wind shadow area on the northwest side was larger, which also affected many surrounding buildings and areas. In response to this situation, overhead or reconstructed holes can be made on the ground floor or middle floor of B6 to connect the space environment on both sides. Figure 16(a) is the original wind velocity contour map, and Figure 16(b) is the optimized wind velocity contour image. Observed from Figure 16, after optimization processing, the area of the wind shadow area around B6 has been reduced more. This measure can effectively adjust the amount and speed of wind entering the wind shadow area, buffer the wind pressure difference between the windward and leeward sides of buildings, reduce the area of wind shadow, and improve the quality of wind environment. Meanwhile, these overhead spaces can also be used to create comfortable, leisure, and fun spaces. However, attention should be paid to the implementation of winter insulation measures on these spaces.

5.4. Greening Configuration. Greening is not only an important foundation of the campus landscape but also closely related to the campus wind and heat environment [43]. Studies showed that different combinations of greening and buildings change the roughness of the ground and affect the PLW environment. Therefore, it is possible to improve and optimize the wind environment of the site and building through the arrangement of greening. Plant shading and transpiration adjust the amount of solar radiation absorbed by buildings and the balance of heat and humidity in the environment and thereby change the building load by mitigating the urban heat island and dry island effects $[44,45]$. In addition, greening also acts as a 
wind screen to reduce the amount of cold air infiltration, thereby reducing the building's heat load. When the campus greening is configured, factors such as the plant's morphological characteristics and growth characteristics should be comprehensively considered, and reasonable layout and vertical matching should be carried out.

The simulation results for winter show that the wind speed in the square to the south of B8 was lower, which may lead to a higher content of pollutants; therefore, two rows of deciduous trees can be set at a specific angle on both sides of the square (Figures 11 and 12). Through guiding the wind and purifying air, the plants improve the air quality of the local environment. Shrubs and lawns can be used if there are geological or other challenges in planting tall trees. In addition, there were highspeed wind vortices around D6, D7, E4, and E2 in the winter, so plants can be planted in the prevailing wind to form a threedimensional wind barrier to eliminate or weaken the strong wind. For example, two rows of staggered windbreaks can be set parallel to the campus boundary on the north of E2, and appropriate bushes can also be planted. The simulation results for summer show that the square on the west of B1 was poorly ventilated (Figures 13 and 14). The ground material of the square was cement, so the intense solar radiation in summer resulted in a rapid increase in the temperature of the square. The overall wind and heat comfort were poor. Without affecting the traffic evacuation, plants can be arranged in this square to introduce cool wind into the square and buildings, adjust air humidity and temperature, and increase human comfort.

\section{Conclusions}

The prediction, optimization, design, and renovation of wind environments are essential steps of green campus construction and pedestrian environment improvement and outdoor thermal environment research. Research on the outdoor wind environment in universities is necessary. In this study, the PLW environments in winter and summer were simulated and analyzed on CUMTB campus. Based on the simulation results, the characteristics and problems of the wind environment were examined.

Finally, the corresponding improvement strategies are proposed from the perspectives of planning layout, single building form, building wind shadow area, and greening configuration. (1) As for the overall planning of the campus, in the peripheral interface area with dominant wind direction in winter, building groups or single building forms with strong enclosure should be selected as far as possible to resist excessive cold wind penetration in winter. On the interface of dominant wind direction in summer, it should be kept transparent as far as possible to promote natural ventilation and heat dissipation. (2) In winter, the windward corner of high-rise buildings is prone to form high-speed wind vortex or downdraft. Therefore, in the stage of campus planning and design, excessively narrow roads around high-rise buildings should be avoided to reduce the occurrence of high-speed wind. In the architectural form design, the facade and corner of the windward face of high-rise buildings should be concave-convex to increase damping as much as possible to reduce the undesirable wind effect. (3)
Apartments arranged in rows tend to form a large area of wind shadow, which is not conducive to ventilation, so attention should be paid to adjust the arrangement and position relationship between apartment buildings. (4) Local wind environment can be improved by greening.

The objectives of optimization are to put forward some strategies to improve the outdoor wind environment quality of campus effectively, so as to reduce backflow, downdraft, corner wind, air stagnation zone, eddy, and other bad wind environment in the campus to reduce the adverse effect of wind on the human body and to create a healthy and comfortable wind environment. These strategies can provide reference for the same type of campus on wind environment construction. In addition, the research results can provide data contribution to pedestrian environment optimization and outdoor thermal environment research.

Due to equipment and other circumstances constraints of the author's research team, further and extensive field measurements, simulations, and research work on this campus and others in different countries and cities will be carried out in the future. More indexes will be simulated and measured and detailed research on the independence and interrelationship of multiple indexes will be worked in the future.

\section{Data Availability}

The data used to support the findings of the study are available from the corresponding author upon reasonable request.

\section{Conflicts of Interest}

The authors declare that there are no conflicts of interest regarding the publication of this paper.

\section{Acknowledgments}

This research was supported by the National Natural Science Foundation of China (Grant no. 51778614) and the Program of Students Innovation Training of China (Grant no. C201806085).

\section{References}

[1] B. Blocken, W. D. Janssen, and T. van Hooff, "CFD simulation for pedestrian wind comfort and wind safety in urban areas: general decision framework and case study for the Eindhoven university campus," Environmental Modelling \& Software, vol. 30, pp. 15-34, 2012.

[2] J. Niu, J. Liu, T.-c. Lee et al., "A new method to assess spatial variations of outdoor thermal comfort: onsite monitoring results and implications for precinct planning," Building \& Environment, vol. 91, pp. 263-270, 2015.

[3] B. Givoni, M. Noguchi, H. Saaroni et al., "Outdoor comfort research issues," Energy and Buildings, vol. 35, no. 1, pp. 77-86, 2003.

[4] Y. Gao, R. Yao, B. Li, E. Turkbeyler, Q. Luo, and A. Short, "Field studies on the effect of built forms on urban wind environments," Renewable Energy, vol. 46, pp. 148-154, 2012.

[5] L. Yang and Y. Li, "Thermal conditions and ventilation in an ideal city model of Hong Kong," Energy and Buildings, vol. 43, no. 5, pp. 1139-1148, 2011.

[6] Z. T. Ai and C. M. Mak, "From street canyon microclimate to indoor environmental quality in naturally ventilated urban 
buildings: issues and possibilities for improvement," Building and Environment, vol. 94, no. 2, pp. 489-503, 2015.

[7] E. Ng, "Policies and technical guidelines for urban planning of high-density cities-air ventilation assessment (AVA) of Hong Kong," Building and Environment, vol. 44, no. 7, pp. 1478-1488, 2009.

[8] D. J. Cui, C. M. Mak, K. C. S. Kwok, and Z. T. Ai, “CFD simulation of the effect of an upstream building on the inter-unit dispersion in a multi-story building in two wind directions," Journal of Wind Engineering and Industrial Aerodynamics, vol. 150, pp. 31-41, 2016.

[9] D. Mu, N. Gao, and T. Zhu, "Wind tunnel tests of inter-flat pollutant transmission characteristics in a rectangular multistorey residential building, part A: effect of wind direction," Building and Environment, vol. 108, pp. 159-170, 2016.

[10] B. Blocken, T. Stathopoulos, and J. P. A. J. van Beeck, "Pedestrian-level wind conditions around buildings: review of wind-tunnel and CFD techniques and their accuracy for wind comfort assessment," Building and Environment, vol. 100, pp. 50-81, 2016.

[11] M. Bottema, "A method for optimisation of wind discomfort criteria," Building and Environment, vol. 35, no. 1, pp. 1-18, 2000.

[12] Q. M. Z. Iqbal and A. L. S. Chan, "Pedestrian level wind environment assessment around group of high-rise crossshaped buildings: effect of building shape, separation and orientation," Building \& Environment, vol. 101, pp. 45-63, 2016.

[13] Q. Chen, "Using computational tools to factor wind into architectural environment design," Energy and Buildings, vol. 36, no. 12, pp. 1197-1209, 2004.

[14] B.-J. He, L. Yang, and M. Ye, "Strategies for creating good wind environment around Chinese residences," Sustainable Cities and Society, vol. 10, pp. 174-183, 2014.

[15] T. Shui, J. Liu, Q. Yuan et al., "Assessment of pedestrian-level wind conditions in severe cold regions of China," Building and Environment, vol. 135, pp. 53-67, 2018.

[16] B. Blocken and J. Carmeliet, "Pedestrian wind environment around buildings: literature review and practical examples," Journal of Building Physics, vol. 28, no. 2, pp. 1097-1963, 2004.

[17] T. Kubota, M. Miura, Y. Tominaga, and A. Mochida, "Wind tunnel tests on the relationship between building density and pedestrian-level wind velocity: development of guidelines for realizing acceptable wind environment in residential neighborhood," Building and Environment, vol. 43, no. 10, pp. 1699-1708, 2008.

[18] Y.X. Zhu, Built Environment. Version 3, China Architecture \& Building Press, Beijing, China, 2010.

[19] S. Murakami, Y. Iwasa, and Y. Morikawa, "Study on acceptable criteria for assessing wind environment at ground level based on residents' diaries," Journal of Wind Engineering and Industrial Aerodynamics, vol. 24, no. 1, pp. 1-18, 1986.

[20] S. Sharples and R. Bensalem, "Airflow in courtyard and atrium buildings in the urban environment: a wind tunnel study," Solar Energy, vol. 70, no. 3, pp. 237-244, 2001.

[21] N. J. Jamieson, P. Carpenter, and P. D. Cenek, "The effect of architectural detailing on pedestrian level wind speeds," Journal of Wind Engineering and Industrial Aerodynamics, vol. 44, no. 1-3, pp. 2301-2312, 1992.

[22] X. Y. Ying, Y. L. Wang, W. Z. Li, Z. Q. Liu, and G. Ding, "Group layout pattern and outdoor wind environment of enclosed office buildings in Hangzhou," Energies, vol. 13, no. 2, Article ID 3561395, 2020.
[23] F. Guo, P. Zhu, S. Wang, D. Duan, and Y. Jin, "Improving natural ventilation performance in a high-density urban district: a building morphology method," Procedia Engineering, vol. 205, pp. 952-958, 2017.

[24] C.-Y. Kuo, C.-T. Tzeng, M.-C. Ho, and C.-M. Lai, "Wind tunnel studies of a pedestrian-level wind environment in a street canyon between a high-rise building with a podium and low-level attached houses," Energies, vol. 8, no. 10, pp. 10942-10957, 2015.

[25] 2020, http://www.bjstats.gov.cn/zxfb/201802/t20180225_393332. html.

[26] The Standardization Administration of China, Standard of Climatic Regionalization for Architecture, The Standardization Administration of China, Beijing, China, GB50178-1993, 2005.

[27] Reference Room of Meteorological Information Center of China Meteorological Administration and Department of Architectural Technology of Tsinghua University, China Special Weather Database for Analysis of Building Thermal Environment, China Architecture \& Building Press, Beijing, China, 2005.

[28] W. D. Janssen, B. Blocken, and T. van Hooff, "Pedestrian wind comfort around buildings: comparison of wind comfort criteria based on whole-flow field data for a complex case study," Building and Environment, vol. 59, pp. 547-562, 2013.

[29] H. Montazeri and B. Blocken, "CFD simulation of wind-induced pressure coefficients on buildings with and without balconies: validation and sensitivity analysis," Building and Environment, vol. 60, pp. 137-149, 2013.

[30] 2020, http://www.cham.co.uk/phoenics.php.

[31] Y. Du, C. M. Mak, and Z. Ai, "Modelling of pedestrian level wind environment on a high-quality mesh: a case study for the HKPolyU campus," Environmental Modelling \& Software, vol. 103, pp. 105-119, 2018.

[32] C. J. Keylock, "Flow resistance in natural, turbulent channel flows: the need for a fluvial fluid mechanics," Water Resources Research, vol. 51, no. 6, pp. 4374-4390, 2015.

[33] F. J. Wang, Computational Fluid Dynamics Analysis: The Principle and Application of CFD Software, Tsinghua University Press, Beijing, China, 2004.

[34] A. Mochida, Y. Tominaga, S. Murakami, R. Yoshie, T. Ishihara, and R. Ooka, "Comparison of various $k-\varepsilon$ model and DSM applied to flow around a high-rise building-report on AIJ cooperative project for CFD prediction of wind environment," Wind \& Structures An International Journal, vol. 5, no. 2-4, pp. 227-244, 2002.

[35] Y. Tominaga, A. Mochida, R. Yoshie et al., "AIJ guidelines for practical applications of CFD to pedestrian wind environment around buildings," Journal of Wind Engineering and Industrial Aerodynamics, vol. 96, no. 10-11, pp. 1749-1761, 2008.

[36] B. Mou, B. J. He, D. X. Zhao, and K. w. Chau, "Numerical simulation of the effects of building dimensional variation on wind pressure distribution," Engineering Applications of Computational Fluid Mechanics, vol. 11, no. 1, pp. 15-27, 2017.

[37] The Standardization Administration of China, JGJ/T 449-2018, Standard for Green Performance Calculation of Civil Buildings, The Standardization Administration of China, Beijing, China, 2018.

[38] The Standardization Administration of China, DB11/ 938-2012, Design Standard of Green Building, The Standardization Administration of China, Beijing, China, 2012.

[39] The Standardization Administration of China, GB/ T50378-2019, Assessment Standard for Green Building, The 
Standardization Administration of China, Beijing, China, 2019.

[40] The Standardization Administration of China, CSUS/ GBC04-2013, Evaluation Standard For Green Campus, The Standardization Administration of China, pp. 14-15, Beijing, China, 2013.

[41] M. Bottema, "Wind climate and urban geometry," Ph.D. thesis, Eindhoven University of Technology, Eindhoven, Netherlands, 1980.

[42] B. Hong and B. Lin, "Numerical studies of the outdoor wind environment and thermal comfort at pedestrian level in housing blocks with different building layout patterns and trees arrangement," Renewable Energy, vol. 73, pp. 18-27, 2015.

[43] Y. D. Ke and J. G. Sang, "Numerical simulations of the wind environment around buildings affect ed by a small green belt," Acta Scientiarum Naturalium Universitatis Pekinensis, vol. 44, no. 4, pp. 585-591, 2008.

[44] F. Kong, C. Sun, F. Liu et al., "Energy saving potential of fragmented green spaces due to their temperature regulating ecosystem services in the summer," Applied Energy, vol. 183, pp. 1428-1440, 2016.

[45] J. Song and Z.-H. Wang, "Impacts of mesic and xeric urban vegetation on outdoor thermal comfort and microclimate in Phoenix, AZ," Building and Environment, vol. 94, no. 2, pp. 558-568, 2015. 